\title{
ISDR
}

International Strategy for Disaster Reduction

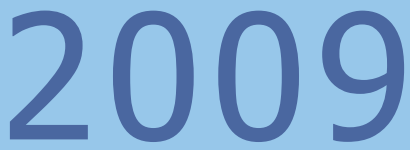

UNISDR

Terminology

on
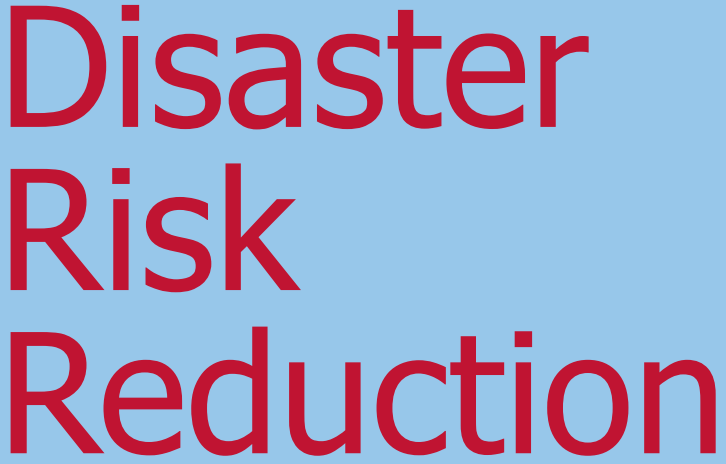
Published by the United Nations International

Strategy for Disaster Reduction (UNISDR)

Geneva, Switzerland, May 2009

(c) United Nations, 2009

(c) United Nations International Strategy

for Disaster Reduction, 2009

All rights reserved

This publication may be freely quoted or reprinted, but acknowledgement of the source is requested.

The UNISDR encourages its reproduction and translation. If any reproductions or translations are generated, a copy of the document is requested to be forwarded to the UNISDR.

The English terminology, and its translations into Arabic, Chinese, French, Russian, and Spanish, are available on the UNISDR website at:

www.unisdr.org/publications

and on PreventionWeb at:

www.preventionweb.net 


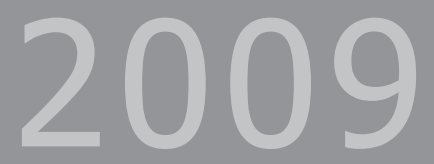

UNISDR

Terminology

Disaster

Risk

Reduction 
घ

口

口

口

口
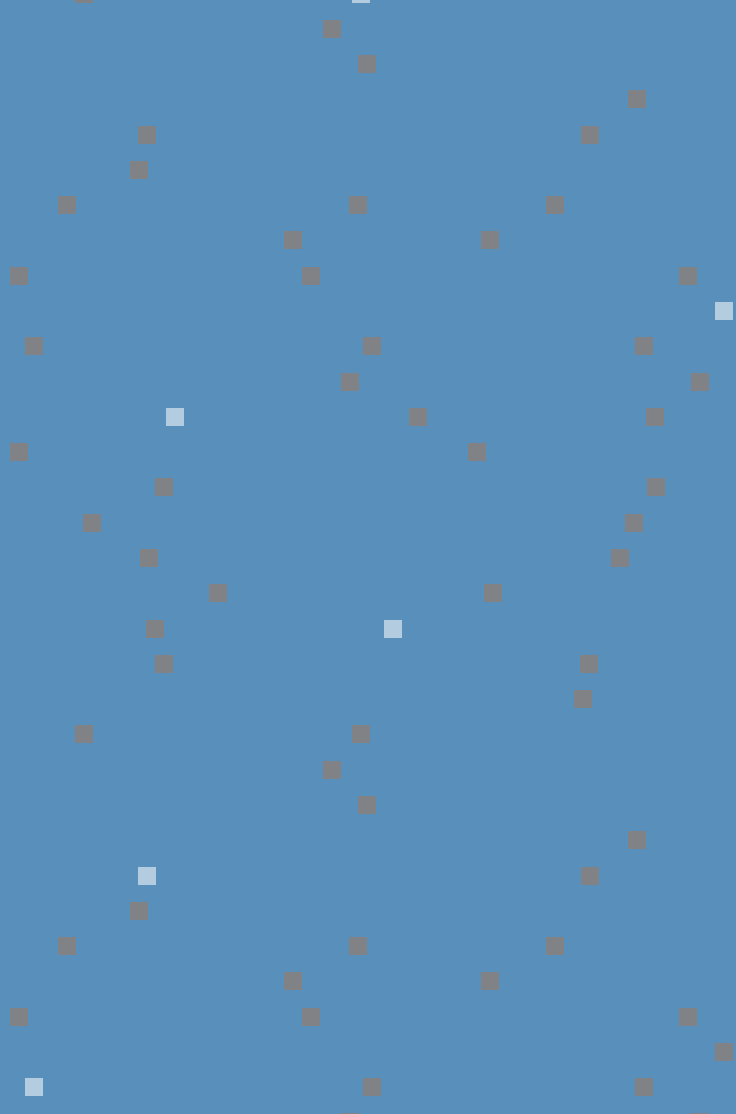

口

口

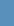


The United Nations International Strategy for Disaster Reduction (UNISDR) Terminology aims to promote common understanding and common usage of disaster risk reduction concepts and to assist the disaster risk reduction efforts of authorities, practitioners and the public. The previous version "Terminology: Basic terms of disaster risk reduction" was published in "Living with risk: a global review of disaster risk reduction initiatives" in 2004. The following year, the Hyogo Framework for Action 2005-2015 requested the UNISDR to "update and widely disseminate international standard terminology related to disaster risk reduction, at least in all official United Nations languages, for use in programme and institutions development, operations, research, training curricula and public information programmes".

The 2009 version is the result of a process of ongoing review by the UNISDR and consultations with a broad range of experts and practitioners in various international venues, regional discussions and national settings. The terms are now defined by a single sentence. The comments paragraph associated with each term is not part of the definition, but is provided to give additional context, qualification and explanation. It should be noted that the terms are not necessarily mutually exclusive, and in some cases may have overlapping meanings.

The Terminology has been revised to include words that are central to the contemporary understanding and evolving practice of disaster risk reduction but exclude words that have a common dictionary usage. Also included are a number of emerging new concepts that are not in widespread use but are of growing professional relevance; these terms are marked with a star $(*)$ and their definition may evolve in future. The English version of the 2009 Terminology provides the basis for the preparation of other language versions. Comments and suggestions for future revisions are welcome and should be directed to the UNISDR (see www.unisdr.org). 


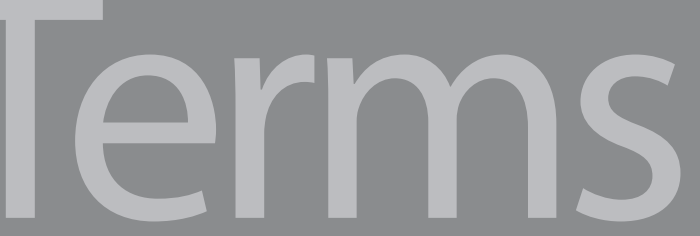

Acceptable risk 04 Adaptation 04

Biological hazard $04 \quad$ Building code 05

Capacity 05 Capacity Development 06 Climate change 06 Contingency planning 07 Coping capacity 08 Corrective disaster risk management* $08 \square$ Critical facilities 08

Disaster 09 — Disaster risk 09 — Disaster risk management $10 \backsim$ Disaster risk reduction 10 Disaster risk reduction plan* 11

Early warning system 12 Ecosystem services 12 El Niño-Southern Oscillation phenomenon 13 Emergency management 13 Emergency services 14 Environmental degradation 14 Environmental impact assessment 15 Exposure 15 Extensive risk* 15

\section{Forecast 16}

Geological hazard 16 Greenhouse gases 17

Hazard $17 \square$ Hydrometeorological hazard 18

* Emerging new concepts that are not in widespread use but are of growing professional relevance; the definition of these terms remain to be widely consulted upon and may change in future. 


\section{Intensive risk* 18}

Land-use planning 19

Mitigation 19

National platform for disaster risk reduction 20

Natural hazard 20

Preparedness 21 a Prevention 22

Prospective disaster risk management* 22

Public awareness 22

Recovery 23 Residual risk 23 Resilience 24

$\square$ Response $24 \square$ Retrofitting $25 \square$ Risk 25 Risk assessment $26 \square$ Risk management 26 Risk transfer 27

Socio-natural hazard* $27 \quad$ Structural and non-structural measures 28 Sustainable development 29

Technological hazard 29

Vulnerability 30 


\section{Acceptable risk}

The level of potential losses that a society or community considers acceptable given existing social, economic, political, cultural, technical and environmental conditions.

Comment: In engineering terms, acceptable risk is also used to assess and define the structural and non-structural measures that are needed in order to reduce possible harm to people, property, services and systems to a chosen tolerated level, according to codes or "accepted practice" which are based on known probabilities of hazards and other factors.

\section{Adaptation}

The adjustment in natural or human systems in response to actual or expected climatic stimuli or their effects, which moderates harm or exploits beneficial opportunities.

Comment: This definition addresses the concerns of climate change and is sourced from the secretariat of the United Nations Framework Convention on Climate Change (UNFCCC). The broader concept of adaptation also applies to non-climatic factors such as soil erosion or surface subsidence. Adaptation can occur in autonomous fashion, for example through market changes, or as a result of intentional adaptation policies and plans. Many disaster risk reduction measures can directly contribute to better adaptation.

\section{Biological hazard}

Process or phenomenon of organic origin or conveyed by biological vectors, including exposure to pathogenic micro-organisms, 
toxins and bioactive substances that may cause loss of life, injury, illness or other health impacts, property damage, loss of livelihoods and services, social and economic disruption, or environmental damage.

Comment: Examples of biological hazards include outbreaks of epidemic diseases, plant or animal contagion, insect or other animal plagues and infestations.

\section{Building code}

A set of ordinances or regulations and associated standards intended to control aspects of the design, construction, materials, alteration and occupancy of structures that are necessary to ensure human safety and welfare, including resistance to collapse and damage.

Comment: Building codes can include both technical and functional standards. They should incorporate the lessons of international experience and should be tailored to national and local circumstances. A systematic regime of enforcement is a critical supporting requirement for effective implementation of building codes.

\section{Capacity}

The combination of all the strengths, attributes and resources available within a community, society or organization that can be used to achieve agreed goals.

Comment: Capacity may include infrastructure and 
physical means, institutions, societal coping abilities, as well as human knowledge, skills and collective attributes such as social relationships, leadership and management. Capacity also may be described as capability. Capacity assessment is a term for the process by which the capacity of a group is reviewed against desired goals, and the capacity gaps are identified for further action.

\section{Capacity Development}

The process by which people, organizations and society systematically stimulate and develop their capacities over time to achieve social and economic goals, including through improvement of knowledge, skills, systems, and institutions.

Comment: Capacity development is a concept that extends the term of capacity building to encompass all aspects of creating and sustaining capacity growth over time. It involves learning and various types of training, but also continuous efforts to develop institutions, political awareness, financial resources, technology systems, and the wider social and cultural enabling environment.

\section{Climate change}

(a) The Inter-governmental Panel on Climate Change (IPCC) defines climate change as: "a change in the state of the climate that can be identified (e.g., by using statistical tests) by changes in the mean and/or the variability of its properties, and that persists for an extended period, typically decades or longer. Climate change may be due to natural 
internal processes or external forcings, or to persistent anthropogenic changes in the composition of the atmosphere or in land use".

(b) The United Nations Framework

Convention on Climate Change (UNFCCC) defines climate change as "a change of climate which is attributed directly or indirectly to human activity that alters the composition of the global atmosphere and which is in addition to natural climate variability observed over comparable time periods".

Comment: For disaster risk reduction purposes, either of these definitions may be suitable, depending on the particular context. The UNFCCC definition is the more restricted one as it excludes climate changes attributable to natural causes. The IPCC definition can be paraphrased for popular communications as "A change in the climate that persists for decades or longer, arising from either natural causes or human activity."

\section{Contingency planning}

A management process that analyses specific potential events or emerging situations that might threaten society or the environment and establishes arrangements in advance to enable timely, effective and appropriate responses to such events and situations.

Comment: Contingency planning results in organized and coordinated courses of action with clearlyidentified institutional roles and resources, information processes, and operational arrangements for specific actors at times of need. Based on scenarios of possible emergency conditions or disaster events, it allows key 
actors to envision, anticipate and solve problems that can arise during crises. Contingency planning is an important part of overall preparedness. Contingency plans need to be regularly updated and exercised.

\section{Coping capacity}

The ability of people, organizations and systems, using available skills and resources, to face and manage adverse conditions, emergencies or disasters.

Comment: The capacity to cope requires continuing awareness, resources and good management, both in normal times as well as during crises or adverse conditions. Coping capacities contribute to the reduction of disaster risks.

\section{Corrective disaster risk management *}

Management activities that address and seek to correct or reduce disaster risks which are already present.

Comment: This concept aims to distinguish between the risks that are already present, and which need to be managed and reduced now, and the prospective risks that may develop in future if risk reduction policies are not put in place. See also Prospective risk management.

\section{Critical facilities}

The primary physical structures, technical facilities and systems which are socially, 
economically or operationally essential to the functioning of a society or community, both in routine circumstances and in the extreme circumstances of an emergency.

Comment: Critical facilities are elements of the infrastructure that support essential services in a society. They include such things as transport systems, air and sea ports, electricity, water and communications systems, hospitals and health clinics, and centres for fire, police and public administration services.

\section{Disaster}

A serious disruption of the functioning of a community or a society involving widespread human, material, economic or environmental losses and impacts, which exceeds the ability of the affected community or society to cope using its own resources.

Comment: Disasters are often described as a result of the combination of: the exposure to a hazard; the conditions of vulnerability that are present; and insufficient capacity or measures to reduce or cope with the potential negative consequences. Disaster impacts may include loss of life, injury, disease and other negative effects on human physical, mental and social well-being, together with damage to property, destruction of assets, loss of services, social and economic disruption and environmental degradation.

\section{Disaster risk}

The potential disaster losses, in lives, health status, livelihoods, assets and services, which 
could occur to a particular community or a society over some specified future time period.

Comment: The definition of disaster risk reflects the concept of disasters as the outcome of continuously present conditions of risk. Disaster risk comprises different types of potential losses which are often difficult to quantify. Nevertheless, with knowledge of the prevailing hazards and the patterns of population and socio-economic development, disaster risks can be assessed and mapped, in broad terms at least.

\section{Disaster risk management}

The systematic process of using administrative directives, organizations, and operational skills and capacities to implement strategies, policies and improved coping capacities in order to lessen the adverse impacts of hazards and the possibility of disaster.

Comment: This term is an extension of the more general term "risk management" to address the specific issue of disaster risks. Disaster risk management aims to avoid, lessen or transfer the adverse effects of hazards through activities and measures for prevention, mitigation and preparedness.

\section{Disaster risk reduction}

The concept and practice of reducing disaster risks through systematic efforts to analyse and manage the causal factors of disasters, including through reduced exposure to 
hazards, lessened vulnerability of people and property, wise management of land and the environment, and improved preparedness for adverse events.

Comment: A comprehensive approach to reduce disaster risks is set out in the United Nations-endorsed Hyogo Framework for Action, adopted in 2005, whose expected outcome is "The substantial reduction of disaster losses, in lives and the social, economic and environmental assets of communities and countries." The International Strategy for Disaster Reduction (ISDR) system provides a vehicle for cooperation among Governments, organisations and civil society actors to assist in the implementation of the Framework. Note that while the term "disaster reduction" is sometimes used, the term "disaster risk reduction" provides a better recognition of the ongoing nature of disaster risks and the ongoing potential to reduce these risks.

\section{Disaster risk reduction plan *}

A document prepared by an authority, sector, organization or enterprise that sets out goals and specific objectives for reducing disaster risks together with related actions to accomplish these objectives.

Comment: Disaster risk reduction plans should be guided by the Hyogo Framework and considered and coordinated within relevant development plans, resource allocations and programme activities.

National level plans needs to be specific to each level of administrative responsibility and adapted to the different social and geographical circumstances that are present. The time frame and responsibilities for implementation and the sources of funding should be specified in the plan. Linkages to climate change adaptation plans should be made where possible. 


\section{Early warning system}

The set of capacities needed to generate and disseminate timely and meaningful warning information to enable individuals, communities and organizations threatened by a hazard to prepare and to act appropriately and in sufficient time to reduce the possibility of harm or loss.

Comment: This definition encompasses the range of factors necessary to achieve effective responses to warnings. A people-centred early warning system necessarily comprises four key elements: knowledge of the risks; monitoring, analysis and forecasting of the hazards; communication or dissemination of alerts and warnings; and local capabilities to respond to the warnings received. The expression "end-toend warning system" is also used to emphasize that warning systems need to span all steps from hazard detection through to community response.

\section{Ecosystem services}

\section{The benefits that people and communities obtain from ecosystems.}

Comment: This definition is drawn from the Millennium Ecosystem Assessment. The benefits that ecosystems can provide include "regulating services" such as regulation of floods, drought, land degradation and disease, along with "provisioning services" such as food and water, "supporting services" such as soil formation and nutrient cycling, and "cultural services" such as recreational, spiritual, religious and other non-material benefits. Integrated management of land, water and living resources that promotes conservation and sustainable use provide the basis for maintaining ecosystem services, including those that contribute to reduced disaster risks. 


\section{El Niño-Southern Oscillation phenomenon}

A complex interaction of the tropical Pacific Ocean and the global atmosphere that results in irregularly occurring episodes of changed ocean and weather patterns in many parts of the world, often with significant impacts over many months, such as altered marine habitats, rainfall changes, floods, droughts, and changes in storm patterns.

Comment: The El Niño part of the El Niño-Southern Oscillation (ENSO) phenomenon refers to the wellabove-average ocean temperatures that occur along the coasts of Ecuador, Peru and northern Chile and across the eastern equatorial Pacific Ocean, while La Niña part refers to the opposite circumstances when well-below-average ocean temperatures occur. The Southern Oscillation refers to the accompanying changes in the global air pressure patterns that are associated with the changed weather patterns experienced in different parts of the world.

\section{Emergency management}

The organization and management of resources and responsibilities for addressing all aspects of emergencies, in particular preparedness, response and initial recovery steps.

Comment: A crisis or emergency is a threatening condition that requires urgent action. Effective emergency action can avoid the escalation of an event into a disaster. Emergency management involves plans and institutional arrangements to engage and guide the efforts of government, non-government, voluntary and private agencies in comprehensive and coordinated ways to respond to the entire 

emergency management.

\section{Emergency services}

The set of specialized agencies that have specific responsibilities and objectives in serving and protecting people and property in emergency situations.

Comment: Emergency services include agencies such as civil protection authorities, police, fire, ambulance, paramedic and emergency medicine services, Red Cross and Red Crescent societies, and specialized emergency units of electricity, transportation, communications and other related services organizations.

\section{Environmental degradation}

The reduction of the capacity of the environment to meet social and ecological objectives and needs.

Comment: Degradation of the environment can alter the frequency and intensity of natural hazards and increase the vulnerability of communities. The types of human-induced degradation are varied and include land misuse, soil erosion and loss, desertification, wildland fires, loss of biodiversity, deforestation, mangrove destruction, land, water and air pollution, climate change, sea level rise and ozone depletion. 


\section{Environmental impact assessment}

Process by which the environmental consequences of a proposed project or programme are evaluated, undertaken as an integral part of planning and decisionmaking processes with a view to limiting or reducing the adverse impacts of the project or programme.

Comment: Environmental impact assessment is a policy tool that provides evidence and analysis of environmental impacts of activities from conception to decision-making. It is utilized extensively in national programming and project approval processes and for international development assistance projects. Environmental impact assessments should include detailed risk assessments and provide alternatives, solutions or options to deal with identified problems.

\section{Exposure}

People, property, systems, or other elements present in hazard zones that are thereby subject to potential losses.

Comment: Measures of exposure can include the number of people or types of assets in an area. These can be combined with the specific vulnerability of the exposed elements to any particular hazard to estimate the quantitative risks associated with that hazard in the area of interest.

\section{Extensive risk *}

The widespread risk associated with the exposure of dispersed populations to repeated or persistent hazard conditions 
of low or moderate intensity, often of a highly localized nature, which can lead to debilitating cumulative disaster impacts.

Comment: Extensive risk is mainly a characteristic of rural areas and urban margins where communities are exposed to, and vulnerable to, recurring localised floods, landslides storms or drought. Extensive risk is often associated with poverty, urbanization and environmental degradation. See also "Intensive risk".

\section{Forecast}

Definite statement or statistical estimate of the likely occurrence of a future event or conditions for a specific area.

Comment: In meteorology a forecast refers to a future condition, whereas a warning refers to a potentially dangerous future condition.

\section{Geological hazard}

Geological process or phenomenon that may cause loss of life, injury or other health impacts, property damage, loss of livelihoods and services, social and economic disruption, or environmental damage.

Comment: Geological hazards include internal earth processes, such as earthquakes, volcanic activity and emissions, and related geophysical processes such as mass movements, landslides, rockslides, surface collapses, and debris or mud flows. Hydrometeorological factors are important contributors to some of these processes. Tsunamis are difficult to categorize; although they are triggered by undersea earthquakes and other geological 
events, they are essentially an oceanic process that is manifested as a coastal water-related hazard.

\section{Greenhouse gases}

Gaseous constituents of the atmosphere, both natural and anthropogenic, that absorb and emit radiation of thermal infrared radiation emitted by the Earth's surface, the atmosphere itself, and by clouds.

Comment: This is the definition of the Intergovernmental Panel on Climate Change (IPCC). The main greenhouse gases (GHG) are water vapour, carbon dioxide, nitrous oxide, methane and ozone.

\section{Hazard}

A dangerous phenomenon, substance, human activity or condition that may cause loss of life, injury or other health impacts, property damage, loss of livelihoods and services, social and economic disruption, or environmental damage.

Comment: The hazards of concern to disaster risk reduction as stated in footnote 3 of the Hyogo Framework are "... hazards of natural origin and related environmental and technological hazards and risks." Such hazards arise from a variety of geological, meteorological, hydrological, oceanic, biological, and technological sources, sometimes acting in combination. In technical settings, hazards are described quantitatively by the likely frequency of occurrence of different intensities for different areas, as determined from historical data or scientific analysis. 
See other hazard-related terms in the Terminology:

Biological hazard; Geological hazard;

Hydrometeorological hazard; Natural hazard; Socio-

natural hazard; Technological hazard.

\section{Hydrometeorological hazard}

Process or phenomenon of atmospheric, hydrological or oceanographic nature that may cause loss of life, injury or other health impacts, property damage, loss of livelihoods and services, social and economic disruption, or environmental damage.

Comment: Hydrometeorological hazards include tropical cyclones (also known as typhoons and hurricanes), thunderstorms, hailstorms, tornados, blizzards, heavy snowfall, avalanches, coastal storm surges, floods including flash floods, drought, heatwaves and cold spells. Hydrometeorological conditions also can be a factor in other hazards such as landslides, wildland fires, locust plagues, epidemics, and in the transport and dispersal of toxic substances and volcanic eruption material

\section{Intensive risk *}

The risk associated with the exposure of large concentrations of people and economic activities to intense hazard events, which can lead to potentially catastrophic disaster impacts involving high mortality and asset loss.

Comment: Intensive risk is mainly a characteristic of large cities or densely populated areas that are not only exposed to intense hazards such as strong earthquakes, active volcanoes, heavy floods, 
tsunamis, or major storms but also have high levels of vulnerability to these hazards. See also "Extensive risk."

\section{Land-use planning}

The process undertaken by public authorities to identify, evaluate and decide on different options for the use of land, including consideration of long term economic, social and environmental objectives and the implications for different communities and interest groups, and the subsequent formulation and promulgation of plans that describe the permitted or acceptable uses.

Comment: Land-use planning is an important contributor to sustainable development. It involves studies and mapping; analysis of economic, environmental and hazard data; formulation of alternative land-use decisions; and design of long-range plans for different geographical and administrative scales. Land-use planning can help to mitigate disasters and reduce risks by discouraging settlements and construction of key installations in hazard-prone areas, including consideration of service routes for transport, power, water, sewage and other critical facilities.

\section{Mitigation}

The lessening or limitation of the adverse impacts of hazards and related disasters.

Comment: The adverse impacts of hazards often cannot be prevented fully, but their scale or severity can be substantially lessened by various strategies and actions. Mitigation measures encompass engineering techniques and hazard-resistant construction as 
well as improved environmental policies and public awareness. It should be noted that in climate change policy, "mitigation" is defined differently, being the term used for the reduction of greenhouse gas emissions that are the source of climate change.

\section{National platform for disaster risk reduction}

A generic term for national mechanisms for coordination and policy guidance on disaster risk reduction that are multi-sectoral and inter-disciplinary in nature, with public, private and civil society participation involving all concerned entities within a country.

Comment: This definition is derived from footnote 10 of the Hyogo Framework. Disaster risk reduction requires the knowledge, capacities and inputs of a wide range of sectors and organisations, including United Nations agencies present at the national level, as appropriate. Most sectors are affected directly or indirectly by disasters and many have specific responsibilities that impinge upon disaster risks. National platforms provide a means to enhance national action to reduce disaster risks, and they represent the national mechanism for the International Strategy for Disaster Reduction.

\section{Natural hazard}

Natural process or phenomenon that may cause loss of life, injury or other health impacts, property damage, loss of livelihoods and services, social and economic disruption, or environmental damage. 
Comment: Natural hazards are a sub-set of all hazards. The term is used to describe actual hazard events as well as the latent hazard conditions that may give rise to future events. Natural hazard events can be characterized by their magnitude or intensity, speed of onset, duration, and area of extent. For example, earthquakes have short durations and usually affect a relatively small region, whereas droughts are slow to develop and fade away and often affect large regions. In some cases hazards may be coupled, as in the flood caused by a hurricane or the tsunami that is created by an earthquake.

\section{Preparedness}

The knowledge and capacities developed by governments, professional response and recovery organizations, communities and individuals to effectively anticipate, respond to, and recover from, the impacts of likely, imminent or current hazard events or conditions.

Comment: Preparedness action is carried out within the context of disaster risk management and aims to build the capacities needed to efficiently manage all types of emergencies and achieve orderly transitions from response through to sustained recovery. Preparedness is based on a sound analysis of disaster risks and good linkages with early warning systems, and includes such activities as contingency planning, stockpiling of equipment and supplies, the development of arrangements for coordination, evacuation and public information, and associated training and field exercises. These must be supported by formal institutional, legal and budgetary capacities. The related term "readiness" describes the ability to quickly and appropriately respond when required. 


\section{Prevention}

The outright avoidance of adverse impacts of hazards and related disasters.

Comment: Prevention (i.e. disaster prevention) expresses the concept and intention to completely avoid potential adverse impacts through action taken in advance. Examples include dams or embankments that eliminate flood risks, land-use regulations that do not permit any settlement in high risk zones, and seismic engineering designs that ensure the survival and function of a critical building in any likely earthquake. Very often the complete avoidance of losses is not feasible and the task transforms to that of mitigation. Partly for this reason, the terms prevention and mitigation are sometimes used interchangeably in casual use.

\section{Prospective disaster risk management *}

Management activities that address and seek to avoid the development of new or increased disaster risks.

Comment: This concept focuses on addressing risks that may develop in future if risk reduction policies are not put in place, rather than on the risks that are already present and which can be managed and reduced now. See also Corrective disaster risk management.

\section{Public awareness}

The extent of common knowledge about disaster risks, the factors that lead to disasters and the actions that can be taken individually 
and collectively to reduce exposure and vulnerability to hazards.

Comment: Public awareness is a key factor in effective disaster risk reduction. Its development is pursued, for example, through the development and dissemination of information through media and educational channels, the establishment of information centres, networks, and community or participation actions, and advocacy by senior public officials and community leaders.

\section{Recovery}

The restoration, and improvement where appropriate, of facilities, livelihoods and living conditions of disaster-affected communities, including efforts to reduce disaster risk factors.

Comment: The recovery task of rehabilitation and reconstruction begins soon after the emergency phase has ended, and should be based on pre-existing strategies and policies that facilitate clear institutional responsibilities for recovery action and enable public participation. Recovery programmes, coupled with the heightened public awareness and engagement after a disaster, afford a valuable opportunity to develop and implement disaster risk reduction measures and to apply the "build back better" principle.

\section{Residual risk}

The risk that remains in unmanaged form, even when effective disaster risk reduction measures are in place, and for which emergency response and recovery capacities must be maintained. 
Comment: The presence of residual risk implies a continuing need to develop and support effective capacities for emergency services, preparedness, response and recovery together with socio-economic policies such as safety nets and risk transfer mechanisms.

\section{Resilience}

The ability of a system, community or society exposed to hazards to resist, absorb, accommodate to and recover from the effects of a hazard in a timely and efficient manner, including through the preservation and restoration of its essential basic structures and functions.

Comment: Resilience means the ability to "resile from" or "spring back from" a shock. The resilience of a community in respect to potential hazard events is determined by the degree to which the community has the necessary resources and is capable of organizing itself both prior to and during times of need.

\section{Response}

The provision of emergency services and public assistance during or immediately after a disaster in order to save lives, reduce health impacts, ensure public safety and meet the basic subsistence needs of the people affected.

Comment: Disaster response is predominantly focused on immediate and short-term needs and is sometimes called "disaster relief". The division between this response stage and the subsequent recovery stage 
is not clear-cut. Some response actions, such as the supply of temporary housing and water supplies, may extend well into the recovery stage.

\section{Retrofitting}

\section{Reinforcement or upgrading of existing} structures to become more resistant and resilient to the damaging effects of hazards.

Comment: Retrofitting requires consideration of the design and function of the structure, the stresses that the structure may be subject to from particular hazards or hazard scenarios, and the practicality and costs of different retrofitting options. Examples of retrofitting include adding bracing to stiffen walls, reinforcing pillars, adding steel ties between walls and roofs, installing shutters on windows, and improving the protection of important facilities and equipment.

\section{Risk}

The combination of the probability of an event and its negative consequences.

Comment: This definition closely follows the definition of the ISO/IEC Guide 73. The word "risk" has two distinctive connotations: in popular usage the emphasis is usually placed on the concept of chance or possibility, such as in "the risk of an accident"; whereas in technical settings the emphasis is usually placed on the consequences, in terms of "potential losses" for some particular cause, place and period. It can be noted that people do not necessarily share the same perceptions of the significance and underlying causes of different risks.

See other risk-related terms in the Terminology: Acceptable risk; Corrective disaster risk management; 
Disaster risk; Disaster risk management; Disaster risk reduction; Disaster risk reduction plans; Extensive risk; Intensive risk; Prospective disaster risk management; Residual risk; Risk assessment; Risk management; Risk transfer.

\section{Risk assessment}

A methodology to determine the nature and extent of risk by analysing potential hazards and evaluating existing conditions of vulnerability that together could potentially harm exposed people, property, services, livelihoods and the environment on which they depend.

Comment: Risk assessments (and associated risk mapping) include: a review of the technical characteristics of hazards such as their location, intensity, frequency and probability; the analysis of exposure and vulnerability including the physical social, health, economic and environmental dimensions; and the evaluation of the effectiveness of prevailing and alternative coping capacities in respect to likely risk scenarios. This series of activities is sometimes known as a risk analysis process.

\section{Risk management}

The systematic approach and practice of managing uncertainty to minimize potential harm and loss.

Comment: Risk management comprises risk assessment and analysis, and the implementation of strategies and specific actions to control, reduce and transfer risks. It is widely practiced by organizations to minimise risk in investment decisions and to address 
operational risks such as those of business disruption, production failure, environmental damage, social impacts and damage from fire and natural hazards. Risk management is a core issue for sectors such as water supply, energy and agriculture whose production is directly affected by extremes of weather and climate.

\section{Risk transfer}

The process of formally or informally shifting the financial consequences of particular risks from one party to another whereby a household, community, enterprise or state authority will obtain resources from the other party after a disaster occurs, in exchange for ongoing or compensatory social or financial benefits provided to that other party.

Comment: Insurance is a well-known form of risk transfer, where coverage of a risk is obtained from an insurer in exchange for ongoing premiums paid to the insurer. Risk transfer can occur informally within family and community networks where there are reciprocal expectations of mutual aid by means of gifts or credit, as well as formally where governments, insurers, multi-lateral banks and other large risk-bearing entities establish mechanisms to help cope with losses in major events. Such mechanisms include insurance and re-insurance contracts, catastrophe bonds, contingent credit facilities and reserve funds, where the costs are covered by premiums, investor contributions, interest rates and past savings, respectively.

\section{Socio-natural hazard *}

The phenomenon of increased occurrence of certain geophysical and hydrometeorological hazard events, such as landslides, flooding, 
land subsidence and drought, that arise from the interaction of natural hazards with overexploited or degraded land and environmental resources.

Comment: This term is used for the circumstances where human activity is increasing the occurrence of certain hazards beyond their natural probabilities. Evidence points to a growing disaster burden from such hazards. Socio-natural hazards can be reduced and avoided through wise management of land and environmental resources.

\section{Structural and non-structural}

\section{measures}

Structural measures: Any physical construction to reduce or avoid possible impacts of hazards, or application of engineering techniques to achieve hazardresistance and resilience in structures or systems;

Non-structural measures: Any measure not involving physical construction that uses knowledge, practice or agreement to reduce risks and impacts, in particular through policies and laws, public awareness raising, training and education.

Comment: Common structural measures for disaster risk reduction include dams, flood levies, ocean wave barriers, earthquake-resistant construction, and evacuation shelters. Common non-structural measures include building codes, land use planning laws and their enforcement, research and assessment, information resources, and public awareness 
programmes. Note that in civil and structural engineering, the term "structural" is used in a more restricted sense to mean just the load-bearing structure, with other parts such as wall cladding and interior fittings being termed non-structural.

\section{Sustainable development}

Development that meets the needs of the present without compromising the ability of future generations to meet their own needs.

Comment: This definition coined by the 1987 Brundtland Commission is very succinct but it leaves unanswered many questions regarding the meaning of the word development and the social, economic and environmental processes involved. Disaster risk is associated with unsustainable elements of development such as environmental degradation, while conversely disaster risk reduction can contribute to the achievement of sustainable development, through reduced losses and improved development practices.

\section{Technological hazard}

A hazard originating from technological or industrial conditions, including accidents, dangerous procedures, infrastructure failures or specific human activities, that may cause loss of life, injury, illness or other health impacts, property damage, loss of livelihoods and services, social and economic disruption, or environmental damage. 
Comment: Examples of technological hazards include industrial pollution, nuclear radiation, toxic wastes, dam failures, transport accidents, factory explosions, fires, and chemical spills. Technological hazards also may arise directly as a result of the impacts of a natural hazard event.

\section{Vulnerability}

\section{The characteristics and circumstances of} a community, system or asset that make it susceptible to the damaging effects of a hazard.

Comment: There are many aspects of vulnerability, arising from various physical, social, economic, and environmental factors. Examples may include poor design and construction of buildings, inadequate protection of assets, lack of public information and awareness, limited official recognition of risks and preparedness measures, and disregard for wise environmental management. Vulnerability varies significantly within a community and over time. This definition identifies vulnerability as a characteristic of the element of interest (community, system or asset) which is independent of its exposure. However, in common use the word is often used more broadly to include the element's exposure.

* Emerging new concepts that are not in widespread use but are of growing professional relevance; the definition of these terms remain to be widely consulted upon and may change in future. 


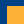

\section{Acaptatioj}

Biolocica

hazard $\square$ Building code a Capacity $\square$ Capacity Development a Climate change u Contingency banning $\square$ Coping capacity $\square$ Corrective disaster risk management a Critical facilities $\square$ Disaster Disaster risk a Disaster risk management _Disaster risk reduction n Disaster risk reduction blan $\square$ Early warning system a Ecosystem services 리 Niño-Southern Oscillation phenomenon Emergency management ם Emergency services Environmental degradation $\quad$ Environmental impact assessment $\square$ Exposure a Extensive risk a Forecast - Geological hazard ¿ Greenhouse gases a Hazard • Hydrometeorological hazard a Intensive risk Land-use planning $\square$ Mitigation $\square$ National platform for disaster risk reduction a Natural hazard Preparedness a Prevention a Prospective disaster risk management $\square$ Public awareness $\square$ Recovery Residual risk $\square$ Resilience $\square$ Response $\square$ Retrofiting Risk $\square$ Risk assessment $\square$ Risk management Risk transfer a Socio-natural hazard a Structural measures a Non-structural measures a Sustainable development 口. Technological hazard a Vulnerability Acceptable risk घ Adaptation $\square$ Biological hazard $\square$ Building code a Capacity a Capacity Development — Climate change u Contingency planning $\square$ Coping capacity $\square$ Corrective disaster risk management - Critical facilities a Disaster Disaster risk ם Disaster risk management Disaster risk reduction a Disaster risk reduction plan $\square$ Early warning system a Ecosystem services El Niño-Southern Oscillation phenomenon Emergency management a Emergency services Environmental deqradation a Environmental risk management _ Public awareness a Recovery Residual risk $\square$ Resilience $\square$ Response $\square$ Retrofitting Risk $\square$ Risk assessment a Risk management

\section{UNISDR Geneva}

Tel. :+41 $229178908 / 8907$ isdr@un.org www.unisdr.org

\section{UNISDR Liaison Office,} New York

palm@un.org

\section{UNISDR Africa, Nairobi}

isdr-africa@unep.org www.unisdr.org/africa
UNISDR Asia and the Pacific, Bangkok isdr-bkk@un.org

www.unisdr.org/asiapacific

UNISDR the Americas,

Panama

eird@eird.org

www.eird.org

\section{UNISDR Europe,}

\section{Geneva}

albrito@un.org

www.unisdr.org/europe

UNISDR West Asia and North Africa, Cairo

info@unisdr-wana.org

www.unisdr.org/wana 